CORRIGENDA

\title{
Corrigendum: Regulatory T cell proliferative potential is impaired in human
} autoimmune disease

Fortunata Carbone, Veronica De Rosa, Pietro B Carrieri, Silvana Montella, Dario Bruzzese, Antonio Porcellini, Claudio Procaccini, Antonio La Cava \& Giuseppe Matarese

Nat. Med. 20, 69-74 (2014); published online 8 December 2013; corrected after print 17 January 2014

In the version of this article published, the data points on the graph in Figure $2 \mathrm{~g}$ were incorrectly labeled. The black data points should be Controls and the gray data points should be RRMS. The error has been corrected in the HTML and PDF versions of the article. 